\section{$\underset{\substack{\text { hommes } \\ \text { \& migrations }}}{ }$}

\section{Hommes \& migrations}

Revue française de référence sur les dynamiques

migratoires

1286-1287 | 2010

Les migrations subsahariennes

\title{
Fatou Diome, Celles qui attendent
}

Paris, Flammarion, 2010, 20 euros

\section{Élisabeth Lesne}

\section{(2) OpenEdition \\ 1 Journals}

\section{Édition électronique}

URL : http://journals.openedition.org/hommesmigrations/1693

DOI : 10.4000/hommesmigrations. 1693

ISSN : 2262-3353

Éditeur

Musée national de l'histoire de l'immigration

\section{Édition imprimée}

Date de publication : 1 juillet 2010

Pagination : 316-137

ISSN : 1142-852X

\section{Référence électronique}

Élisabeth Lesne, «Fatou Diome, Celles qui attendent », Hommes \& migrations [En ligne], 1286-1287|

2010, mis en ligne le 29 mai 2013, consulté le 22 septembre 2020. URL : http://

journals.openedition.org/hommesmigrations/1693; DOI : https://doi.org/10.4000/

hommesmigrations. 1693

Ce document a été généré automatiquement le 22 septembre 2020.

Tous droits réservés 


\title{
Fatou Diome, Celles qui attendent
}

\author{
Paris, Flammarion, 2010, 20 euros
}

\author{
Élisabeth Lesne
}

\section{RÉFÉRENCE}

Fatou Diome, Celles qui attendent, Paris, Flammarion, 2010, 20 euros

1 Une île du Sine-Saloum, au Sénégal, un village où un soleil sans clémence fane les lèvres et où "la faim grignote de l'intérieur", tel est le décor du dernier roman de Fatou Diome, Celles qui attendent, avec en bande son les poules, les canards, les chèvres, les moutons... On y croise des mères désargentées qui vont quémander chez l'épicier Abdou "comme des chamelles attirées par l'oasis", quand elles ne se disputent pas avec leurs concubines, rivales quant à la réussite de leurs fils qu'elles rêvent de marier très vite pour se décharger sur leur bru de leurs tâches ménagères. Mais quel avenir pour ces fils ? La pêche est moins rentable depuis que les chalutiers occidentaux viennent piller les ressources locales, et parmi ceux qui fréquentent l'école, bien rares sont ceux qui décrochent un diplôme et une bourse pour l'étranger. Alors, "ces enfants détournés de la vie paysanne et trop mal outillés pour escompter un destin de bureaucrate, ne voyant aucun chemin susceptible de les mener vers un avenir rassurant [...], se jettent dans l'Atlantique, se ruent vers l'Europe". Et les filles, qui ont encore si peu accès à l'enseignement, comme le déplore Fatou Diome, "horripilées par la désastreuse condition de leur mère, sans pouvoir compter sur elles-mêmes", s'accrochent à ces forcenés de l'exil, quitte à traiter de blaireaux ceux qui restent au village et qui, "portés par une liberté qu'on ne sent que chez soi, travaillent vaillamment et contribuent à l'essor du pays".

2 Fatou Diome donne toutes les clés pour comprendre un système piège, largement perpétué par les femmes, elles-mêmes pourtant les premières victimes. Elle n'écrit pas pour autant la monographie d'un village et encore moins un traité de sociologie, mais un vrai roman avec des personnages dont, au fil des pages, on partage les émois avec de plus en plus d'intérêt et de tendresse. 
3 Si beaucoup de garçons de l'île tentent la traversée pour l'Espagne en pirogue, nous ne suivons que Lamine et Issa, et encore, pas dans leurs galères en Europe, mais - et c'est toute l'originalité de ce roman centré sur les femmes - à travers les rares nouvelles qui parviennent à "celles qui les attendent": leurs mères, Arame et Bougra, et Daba et Coumba, leurs toutes jeunes épouses. Daba a été mariée après le départ de Lamine, alors qu'elle était déjà fiancée, mais comment résister à la demande en mariage d'un homme promis à un bel avenir ? Coumba a juste eu le temps de tomber enceinte avant de voir partir Issa. Elle le retrouvera bien des années plus tard, flanqué d'une deuxième épouse blanche avec le "sex-appeal d'une lotte" et de trois petits métis. Un de leurs compatriotes qui les avait précédés en Espagne ne leur avait-il pas conseillé de miser sur les filles pour se faire héberger, et même, avait-il précisé : "Si vous arrivez à leur passer la bague au doigt, vous serez sauvés." C'est ainsi qu'ils avaient appris à "user de leur corps comme d'un appât", les clichés sur la virilité noire leur facilitant la tâche, et à bomber le torse " comme on déplace une canne à pêche".

4 Dans ce roman, il y a des pages magnifiques sur l'absence : "Coumba se moquait du matin et n'attendait rien du soir. Sa routine, c'était languir encore et toujours. [...] Certains absents possèdent les femmes mieux qu'aucun amant présent", et sur les regrets, parfois, d'Arame, d'avoir poussé son fils à partir.

Alors, l'Europe, un mirage ? Pas si facile de l'affirmer, et Fatou Diome se garde de trancher de façon abrupte, d'autant que Lamine reviendra au pays avec de quoi construire une maison et sortir sa famille de la misère. À quel prix ? On le devine. Mais comment convaincre les "mercenaires de l'espoir" de ne pas aller se jeter dans la "souricière européenne" quand on revient avec de l'argent ?

6 Oui, un très beau roman pour comprendre de quelle manière, sur l'autre rive, avec son lot de misères, d'illusions et de bénéfices, l'exil vient bousculer le monde rural et ses traditions. 